\title{
Respiratory function in systemic lupus erythematosus, scleroderma, and rheumatoid arthritis
}

\author{
OSSI LAITINEN,* YRJÖ SALORINNE, AND HÅKAN POPPIUS \\ From the Third Department of Medicine and the Department of Pulmonary Diseases, University Central \\ Hospital, Helsinki, Finland
}

Pulmonary involvement is a frequent systemic manifestation of connective tissue diseases. The lesions in lungs are nonspecific, characterized by interstitial fibrosis, bronchiolitis, bronchiolectasis, cystic changes, pleural thickening, and variable degrees of vasculitis (Crofton and Douglas, 1969; Bates, Macklem, and Christie, 1971; Popper, Bogdonoff, and Hughes, 1972). Clinical studies on the subject have been performed mainly by radiological techniques (Boyd, Patrick, and Reeves, 1954; Harvey, Shulman, Tumulty, Conley, and Schoenrich, 1954; Tuffanelli and Winkelmann, 1961; Sievers, Aho, Hurri, and Perttala, 1964; Vuorinen and Kalliomäki, 1964; Patterson, Harville, and Pierce, 1965; Rubin and Siegelman, 1969), but in some series respiratory function tests have also been applied (Adhikari, Bianchi, Boushy, Sakamoto, and Lewis, 1962; Brundin, 1970; Popper and others, 1972). The reported frequencies of pulmonary involvement have varied considerably. On the basis of these previous studies it seems that a diffusion defect occurs at an early stage and may be detected even in the absence of radiological changes. In addition, restrictive ventilatory impairment, decrease of pulmonary compliance and arterial hypoxemia have been observed. Reports of detailed analysis of respiratory function in connective tissue diseases are, however, sparse and more or less incomplete.

In the present study, we have chosen typical patients with systemic lupus erythematosus (SLE), scleroderma (SCL), and rheumatoid arthritis (RA) in an attempt to characterize changes in respiratory function in these diseases, and compared the results with the findings in the thorax $x$ ray examinations.

\section{Patients and methods}

The characteristics of the series are given in Table I. Only moderate or severe cases with confirmed diagnosis were accepted in the series. All the patients had had symptoms of their disease for over 1 year and they had been treated in the hospital several times before this examination. Both patients with clinical symptoms of respiratory disease or pathological changes in chest $x$ ray examination and patients without these criteria were included. Patients with

\section{Table I Characteristics of patients}

\begin{tabular}{|c|c|c|c|}
\hline Diagnosis & $S L E$ & $S C L$ & $R A$ \\
\hline No. of cases & 13 & 9 & 10 \\
\hline Males/females & $3 / 10$ & $1 / 8$ & $2 / 8$ \\
\hline Age (yrs) $\begin{array}{l}\text { Mean } \\
\text { Range }\end{array}$ & $\begin{array}{l}43 \\
24-66\end{array}$ & $\begin{array}{l}41 \\
32-61\end{array}$ & $\begin{array}{l}45 \\
24-66\end{array}$ \\
\hline
\end{tabular}

RA fulfilled the ARA criteria for definite classical rheumatoid arthritis (Ropes, Bennett, Cobb, Jacox, and Jessar, 1959). Patients with SLE had signs of multiple systemic involvement of the disease. Tests for LE phenomenon and antinuclear antibodies were positive. SCL patients displayed characteristic clinical symptoms, and the diagnoses were substantiated by positive skin biopsies and by radiological evidence of oesophageal and/or skeletal involvement.

The following respiratory function tests were employed: spirometry (Bernstein Spirometer, Kifa), arterial blood gas analysis (Clark's electrode for oxygen tension $\left(\mathrm{PaO}_{2}\right)$, and equilibration technique for carbon dioxide tension $\left(\mathrm{PaCO}_{2}\right)$, Radiometer), recording of the expiratory carbon dioxide curve by an infra-red analyser (URAS M 4, Haartmann and Braun) with calculation of the arterial-end-tidal $\mathrm{CO}_{2}$ difference in order to assess the magnitude of 'wasted ventilation', and calculation of the distribution index $\mathrm{RCO}_{2}$ (van Meerten 1966) to assess the existence of peripheral airways disease, determination of the transfer factor for carbon monoxide (T1) with the single-breath technique (Ogilvie, Forster, Blakemore, and Morton, 1957), measurement of airway conductance (SGaw) with a constant-volume body plethysmograph (Siemens), and determination of static pulmonary compliance $\left(\mathbf{C}_{(\mathbf{s t})}\right)$ and lung recoil pressure $\left(\mathbf{P}_{(\mathrm{st})} 1\right)$ at total lung capacity with esophageal balloon technique (MilicEmili, Mead, Turner, and Glauser, 1964). Exercise tests were performed with an electrically braked bicycle ergometer (Elema-Schönander) with the patient in the supine position. The load was increased step-wise by $\mathbf{4 0}$ watt every 6 minutes and the test was continued up to the subject's limit of exercise tolerance.

The normal values for respiratory function tests were adopted or modified from the following sources:

Spirometry: Poppius (1965);

Arterial-end-tidal $\mathrm{CO}_{2}$ difference: Poppius, Korhonen, 
(a)
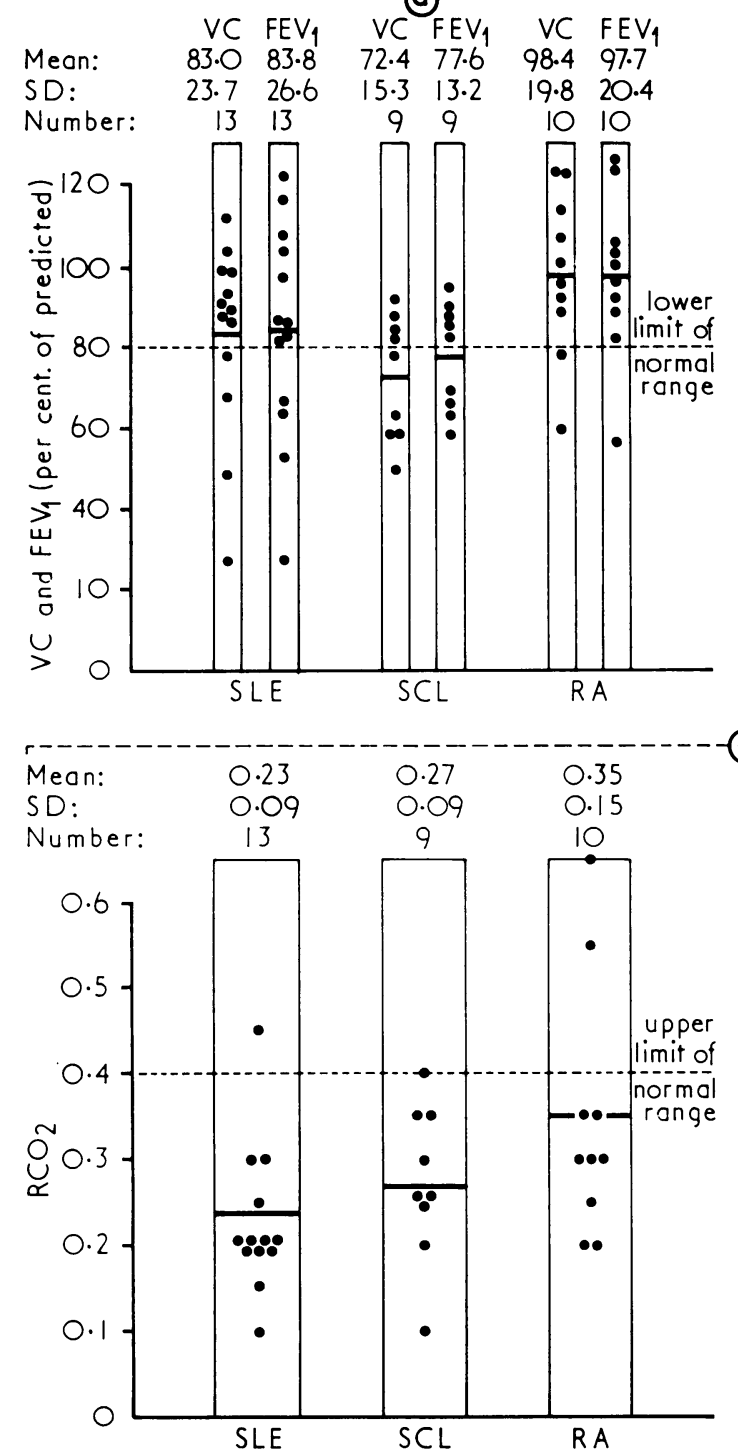

(b)

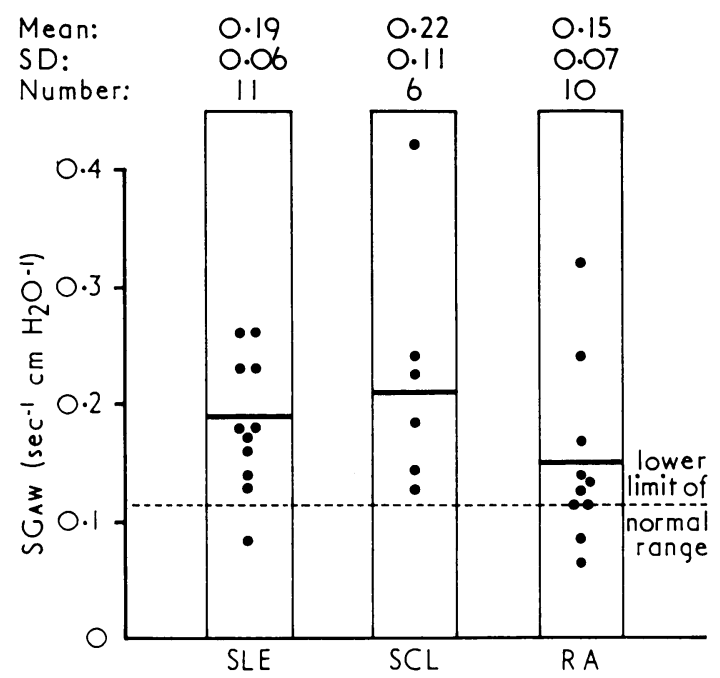

(C)

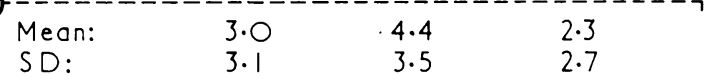

Number: $13 \quad 9 \quad 10$

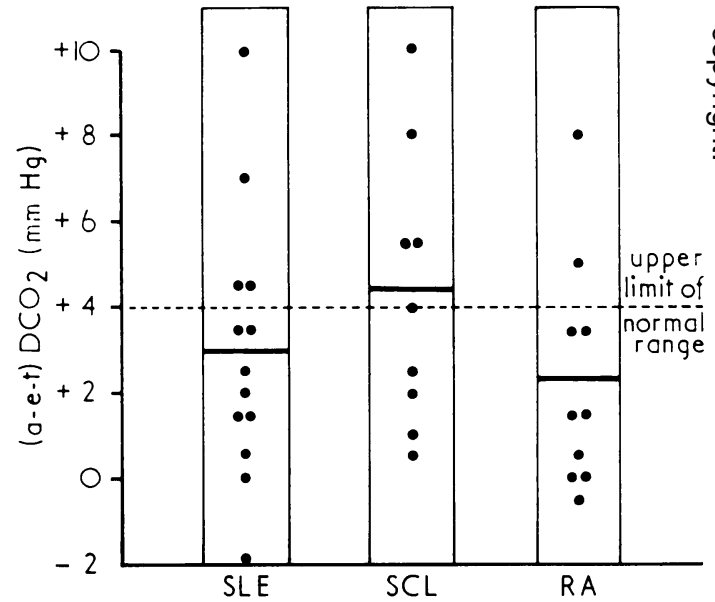

FIG. 1 (a) Spirometrical findings; (b) Specific airway conductance; (c) Distribution index $\mathrm{RCO}_{2}$ and arterial-endtidal $\mathrm{CO}_{2}$ difference $\left((a-e-t) D C O_{2}\right)$ in the three patient groups: $S L E$ (systemic lupus erythematosus), SCL (scleroderma), and RA (rheumatoid arthritis).

Horizontal lines indicate mean values and dotted lines the limits of normal range used in our laboratory

Table II Spirometrical findings and transfer factor values in SLE, SCL, and RA

\begin{tabular}{|c|c|c|c|c|c|c|}
\hline \multirow[t]{2}{*}{ Diagnosis } & \multicolumn{2}{|c|}{$S L E(13)$} & \multicolumn{2}{|c|}{$S C L(9)$} & \multicolumn{2}{|c|}{$R A(10)$} \\
\hline & Mean & $S D$ & Mean & $S D$ & Mean & $S D$ \\
\hline $\begin{array}{l}\text { VC, } 1 \text { BTPS } \\
\text { FEV } 1,1 \text { BTPS } \\
\text { FEV (per cent.) } \\
\text { T1 (ml./min./mm. Hg) }\end{array}$ & $\begin{array}{l}3 \cdot 30 \\
2 \cdot 62 \\
81 \cdot 9 \\
19 \cdot 2^{*}\end{array}$ & $\begin{array}{l}1 \cdot 24 \\
1 \cdot 11 \\
9 \cdot 8 \\
7 \cdot 3\end{array}$ & $\begin{array}{l}2 \cdot 83 \\
2 \cdot 40 \\
86 \cdot 9 \\
14 \cdot 3 \dagger\end{array}$ & $\begin{array}{l}0 \cdot 95 \\
0 \cdot 70 \\
5 \cdot 1 \\
7 \cdot 6\end{array}$ & $\begin{array}{l}3 \cdot 82 \\
3 \cdot 02 \\
79 \cdot 5 \\
24 \cdot 8\end{array}$ & $\begin{array}{c}1 \cdot 25 \\
1 \cdot 01 \\
8 \cdot 3 \\
10 \cdot 4\end{array}$ \\
\hline
\end{tabular}

* Data available in twelve cases. † Data available in five cases. 
Viljanen, and Kreus (in press);

$\mathrm{RCO}_{2}$ : Poppius (1969);

Transfer factor: Cotes (1965);

Airway conductance: Poppius (unpublished data);

Static pulmonary compliance and lung recoil pressure: Wilhelmsen (1968).

With regard to the thorax $x$-ray findings, the patients were arbitrarily divided by two chest physicians into three groups:

Group 0, normal $x$-ray finding;

Group 1, slight reticular parenchymal changes;

Group 2, marked reticular or reticulonodular parenchymal infiltration.

At the time of the $x$-ray assessment the findings in the function tests were not known to the physicians. Two patients in Group 2 and one in Group 1 also had slight radiological pleural changes.

\section{Results}

Vital capacity (VC) and forced expiratory volume in one second $\left(\mathrm{FEV}_{1.0}\right)$ are depicted in Fig. $1(a)$ and Table II. The mean values in the SLE and SCL groups were slightly above and below the lower limit of the normal range, respectively, whereas the mean in the RA group almost coincided with the predicted normal values. Ventilatory impairment, when present, was usually of the restrictive type, i.e. $\mathrm{VC}$ and $\mathrm{FEV}_{\mathbf{1 . 0}}$ were affected to a similar degree. Specific airway conductance (SGaw) was decreased in only three patients (Fig. 1(b)). In two SLE and three SCL patients data of specific airway conductance (SGaw) were not available. The distribution index $\mathrm{RCO}_{2}$ was pathological in the three cases with decreased SGaw values

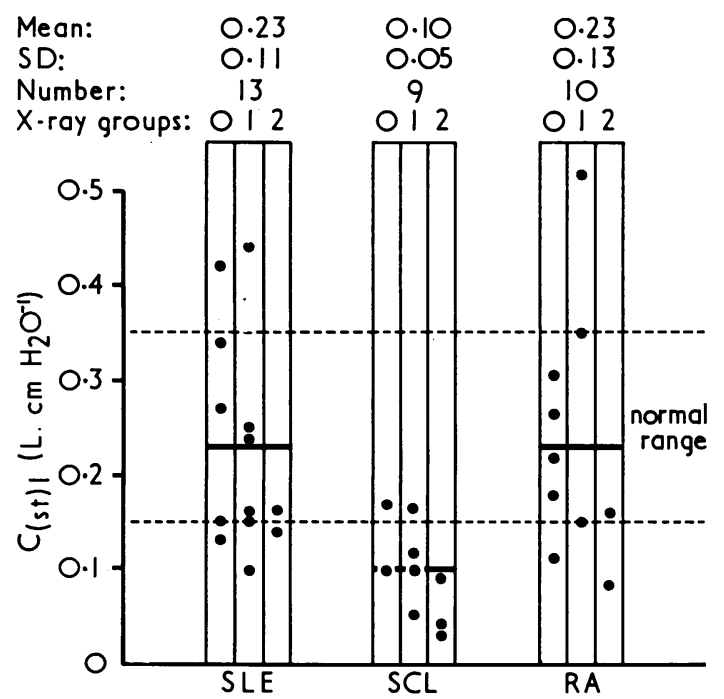

(Fig. $1(c)$ ). The arterial-end-tidal $\mathrm{CO}_{2}$ difference ( (a-e-t)DCO $\left.\mathrm{CO}_{2}\right)$ was increased in one-third of the patients. The highest mean value was found in the SCL group (Fig. $1(c)$ ).

The static pulmonary compliance $\left(\mathrm{C}_{(\mathrm{st})} 1\right)$ in seven of the nine SCL patients (Fig. 2) was below the normal range used in our laboratory. In the RA and SLE groups both high and low values were encountered, most of the findings being within the normal range. When each of the three groups were subdivided on the basis of chest $x$ ray examinations, it was found that the correlation between the pathological findings in the radiological study and those in the compliance test was rather poor; even if all patients with marked findings in the chest $x$ ray examinations (Group 2) showed pathologically low or low-normal compliance values, several cases of SLE and RA with slight radiological changes (Group 1) had high compliance values. Further, in each group one patient with no radiological changes was found to have decreased compliance. In agreement with the results in the compliance measurement high lung recoil pressures $\left(\mathrm{P}_{(\mathrm{st})} 1\right)$ at total lung capacity were recorded in the SCL group, whereas the other groups showed mostly normal values.

Transfer factor (T1) values below the normal range were found in half of the SLE patients and all SCL patients, but in only three of the RA patients (Fig. 3 and Table II). In three SCL patients T1 could not be measured owing to the patients' small vital capacity; these patients probably also had severe transfer defects. In one SLE and in one SCL case,

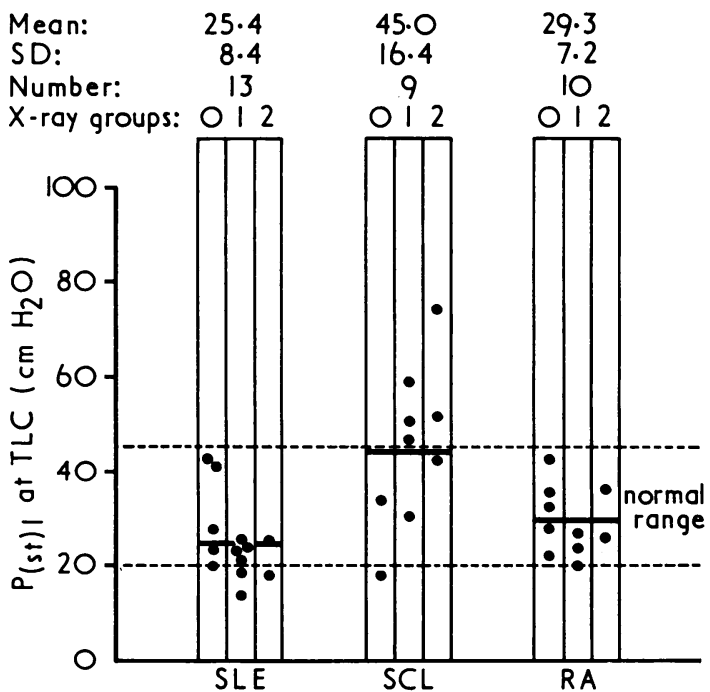

FIG. 2 Static pulmonary compliance $\left(C_{(\mathrm{st})} 1\right)$ and lung recoil pressure at total lung capacity $\left(P_{(\mathrm{s})} 1\right)$ in the three patient groups

Each group is subdivided on the basis of radiological findings: $0=$ normal, $1=$ slight, and $2=$ definite radiological changes

Horizontal lines indicate mean values 
the measurement was technically not acceptable. The correlation between the radiological findings and the $\mathrm{Tl}$ values was poor. Two patients with apparently normal radiological findings had a marked reduction of $\mathrm{Tl}$.

Arterial blood gas values at rest and during exercise are shown in Fig. 4. About half of the patients had slight hypoxaemia at rest $\left(\mathrm{PaO}_{2}<85 \mathrm{~mm}\right.$. $\left.\mathrm{Hg}\right)$. In several cases with SCL and SLE there was a definite decrease of arterial $\mathrm{PO}_{2}$ during exercise; these patients also had low $\mathrm{Tl}$ values.

As a rule, pathological results in different tests were obtained in the same individuals. Respiratory function was considered definitely abnormal in seven of the thirteen SLE patients, in all the nine SCL patients, and in four of the ten RA patients.

\section{Discussion}

The results of this investigation imply that impairment of respiratory function is a common systemic manifestation of connective tissue diseases and can be revealed by appropriate tests. The typical change in respiratory function mainly includes restrictive

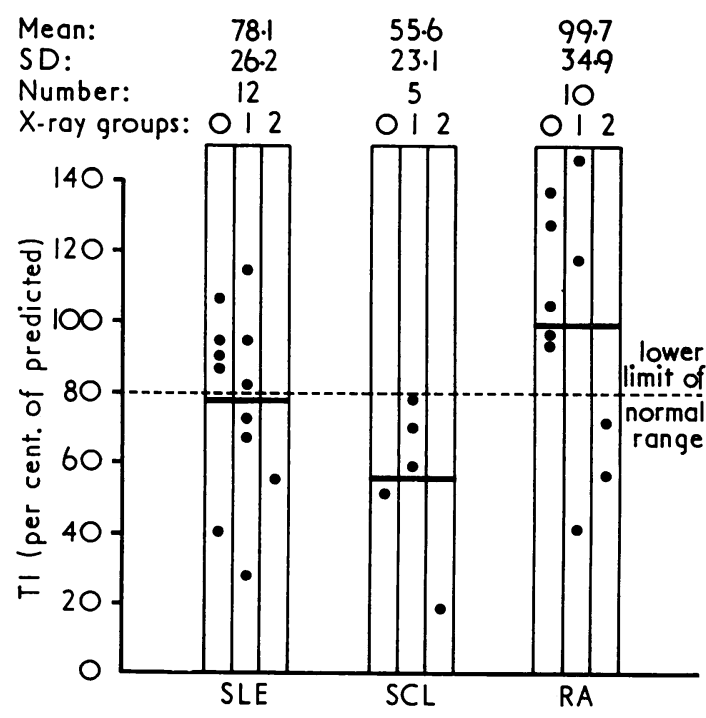

FIG. 3 Transfer factor (T1) values for carbon monoxide. Horizontal lines indicate mean values for respective patient groups. Radiological subdivision as in Fig 2
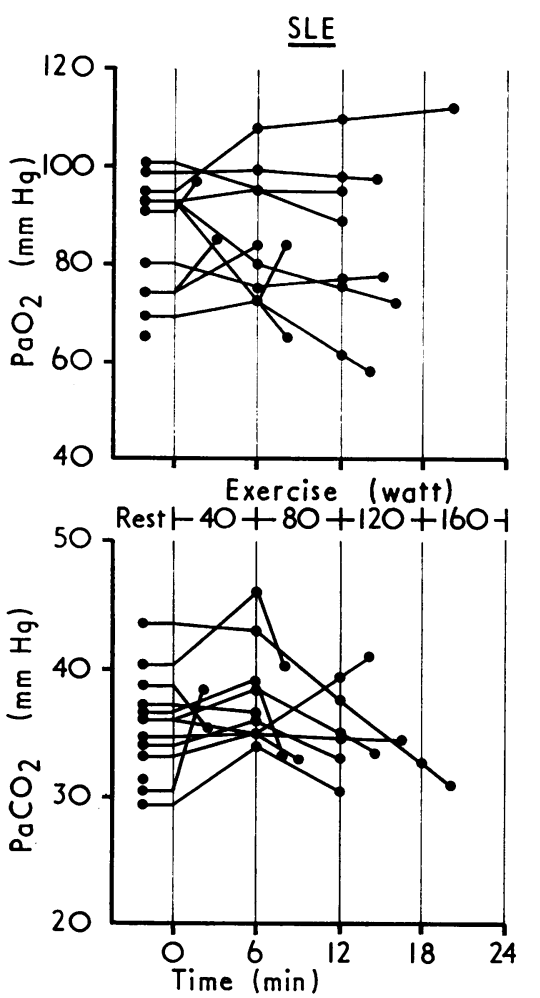

$\underline{\mathrm{SCL}}$

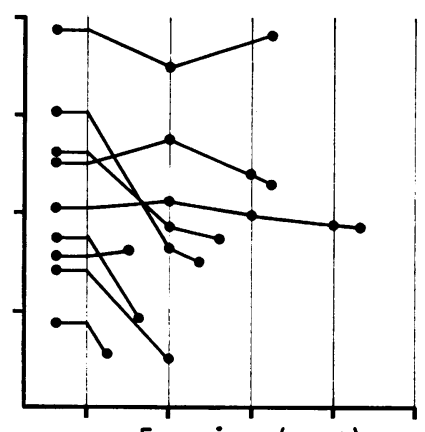

Exercise (watt)

Rest $-40+80+120+160-1$

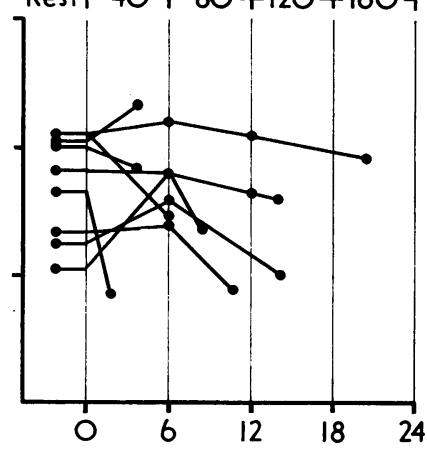

$\underline{\text { RA }}$

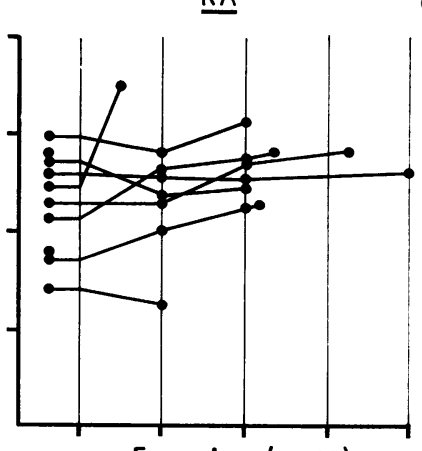

Exercise (watt)

Rest $1-40+80+120+160-1$

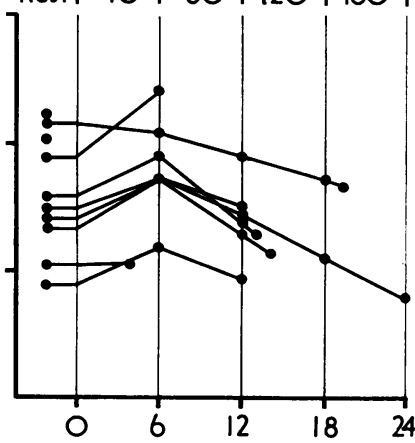

FIG. 4 Arterial oxygen and carbon dioxide tension at rest and during exercise on bicycle ergometer. Load was increased stepwise by 40 watt every 6 min. 
ventilatory impairment, reduced compliance and transfer factor, and progressive hypoxaemia during exercise. Airway conductance and the distribution of gases were mainly normal, excluding major bronchial affection. This combination of findings is compatible with a damage of the lung interstitium.

The respiratory function profile was qualitatively similar in the three disorders suggesting similar structural changes. The disease groups differed, however, with regard to the frequency of significant impairment: reduction of respiratory function was the rule in SCL, and common in SLE, and most normal findings were recorded in the group of RA patients. The poor correlation between the radiological assessment and the transfer factor and compliance measurements suggests that the lungs may be markedly affected without a clear-cut $x$ ray finding and, on the other hand, that significant radiological changes are not always reflected as pathological values in respiratory function tests. Because of the existence of 'radiologically silent' involvement, the reported incidences of a pulmonary affection in connective tissue diseases based on radiological examinations alone may be too small.

Respiratory function studies seem to be a valuable adjunct to radiography in the evaluation of pulmonary involvement in connective tissue diseases. We believe that for practical purposes measurement of transfer factor and vital capacity are the most suitable tests.

\section{Summary}

Thirteen patients with systemic lupus erythematosus (SLE), nine with scleroderma (SCL), and ten with rheumatoid arthritis (RA) were subject to detailed analysis of respiratory function. The typical functional derangement found was compatible with interstitial damage of the lung and included restrictive ventilatory impairment, reduced transfer factor and compliance, and progressive hypoxaemia during exercise, whereas airway conductance and gas distribution were little affected. On the average, the SCL group showed the greatest and the RA group the slightest functional impairment, the type of impairment being essentially the same in the different disease groups. Definitely abnormal respiratory function was found also in the absence of radiologically visible changes. Measurement of transfer factor and vital capacity were considered as the most useful tests for evaluation of respiratory function in these diseases.

\section{References}

Adhikari, P. K., Bianchi, F. A., Boushy, S. F., Sakamoto, A., And Lewis, B. M. (1962) Amer. Rev. resp. Dis., 86, 823 (Pulmonary function in scleroderma)

Bates, D. V., Macklem, P. T., AND Christie, R. V. (1971 'Respiratory Function in Disease', 2nd ed. Saunders, Philadelphia

Boyd, J. A., PATrick, S. I., AND Reeves, R. J. (1954) Arch. intern. Med., 94, 248 (Roentgen changes observed in generalized scleroderma)

Brundin, A. (1970) Scand. J. resp. Dis., 51, 160 (Pulmonary fibrosis in scleroderma and dermatomyositis)

Cotes, J. E. (1965) 'Lung Function. Assessment and Application in Medicine', 1st ed., p. 342. Blackwell, Oxford

Crofton, J., AND Douglas, A. (1969) 'Respiratory Diseases'. Blackwell, Oxford

Harvey, A. M., Shulman, L. E., Tumulty, P. A., Conley, C. L., and Schoenrich, E. H. (1954) Medicine (Baltimore), 33, 291 (Systemic lupus erythematosus: Review of the literature and clinical analysis of 138 cases)

Milic-Emili, J., Mead, J., Turner, J. M., AND Glauser, E. M. (1964) J. appl. Physiol., 19, 207 (Improved technique for estimating pleural pressure from esophageal balloons)

Ogilvie, C. M., Forster, R. E., Blakemore, W. S., AND Morton, J. W. (1957) J. clin. Invest., 36, 1 (A standardized breath holding technique for the clinical measurement of the diffusing capacity of the lung for carbon monoxide)

Patterson, C. D., Harville, W. E., And Pierce, J. A. (1965) Ann. intern. Med., 62, 685 (Rheumatoid lung disease)

Popper, M. S., Bogdonoff, M. L., AND Hughes, R. L. (1972) Chest, 62, 243 (Interstitial rheumatoid lung disease)

Poppius, H. (1965) Ann. Acad. Sci. fenn., A, Suppl. 114 (Airway obstruction, distribution of inspired gas, and physiologic dead space in pulmonary tuberculosis)

- (1969) Scand. J. resp. Dis., 50, 135 (Expiratory $\mathrm{CO}_{2}$ curve in pulmonary diseases)

- Korhonen, O., Viljanen, A., KREUS, K.-E. (in press) Ibid. (Arterial to end-tidal $\mathrm{CO}_{2}$ difference in respiratory disease)

Ropes, M. W., Bennett, G. A., Cobb, S., Jacox, R. ANd Jessar, R. A. (1959) Ann. rheum. Dis., 18, 49 (1958 Revision of diagnostic criteria for rheumatoid arthritis)

Rubin, E. H., AND Siegelman, S. S. (1969) 'Diffuse connective tissue (collagen) diseases (concluded)' in 'The Lungs in Systemic Diseases', chap. 4, p. 83. Thomas, Springfield, Ill.

Sievers, K., Aho, K., Hurri, L., AND Perttala, Y. (1964) Acta tuberc. scand., 45, 21 (Studies of rheumatoid pulmonary disease)

Tuffanelli, D. L., AND Winkelmann, R. K. (1961) Arch. Derm. (Chicago), 84, 359 (Systemic scleroderma: A clinical study of 727 cases)

VAN MEerten, R. J. (1966) 'Nieuwe analytische methoden voor de interpretatie van concentratiecurven van expiratiegasen'. Dissertation. Thoben offset, Nijmegen, Holland

VuORINen, P., AND KalliomäKI, J. L. (1964) A.I.R. (Rio de J.), 7, 73

WilhelmSEN, L. (1968) Acta med. scand., Suppl 489 (Lung mechanics in rheumatic valvular disease) 